\title{
Surviving the Famine unscathed? An Analysis of the Long-term Health Effects of the Great Chinese Famine
}

\author{
Wenli Cheng \& Hui Shi
}

\begin{abstract}
This paper studies the long-term health effects of the Chinese Famine of 1959-1961 on different birth-cohorts exposed to it during different stages of their early childhood.

Based on a 2011 national survey, it finds that exposure to the Famine (1) reduced adult height for all cohorts; (2) had some negative impact on mental health for some cohorts; (3) had no significant effects on the risk of acquiring common chronic diseases for any cohort; (4) had no consistent effects on health related lifestyle choices for any cohort; and (5) lowered the risk of being overweight for 2 out of 5 cohorts. Notably where the effects of the Famine were found to be statistically significant, the magnitudes were small.
\end{abstract}

Keywords: Great Chinese Famine; long-term effect; health; lifestyle choices

Wenli Cheng: Department of Economics, Monash Business School, Monash University, Melbourne Victoria, Australia

Hui Shi: Victoria University 


\section{Introduction}

According to the developmental origins of adult disease hypothesis, also called the Barker hypothesis, developmental plasticity allows an individual to adapt to his/her environment in early life, but this adaptation can also increase the individual's risk of acquiring chronic diseases in adulthood if the environment has changed significantly (Barker 1989, 1992).

Many epidemiological studies of the Barker hypothesis rely on quasi-natural experiments such as famines, epidemics, and natural disasters to assess retrospectively how exposure to these environmental shocks during early stages of life may have affected an individual's health, competence and economic outcomes in adulthood. The available evidence suggest that adverse environmental exposure can have a long-term negative impact. For instance, Almond and Chay (2006) show that U.S. black women with better living conditions in early life enjoyed better health as adults and their children had higher birthweights. Almond (2006) finds that U.S. cohorts exposed to the 1918 influenza pandemic in utero had lower educational attainment and socioeconomic status, and higher rates of physical disability and mortality.

Informed by the Barker hypothesis, this paper studies the long-term health effects of the 1959-61 Chinese Famine ("the Famine" hereafter) on the survivors using the China Health and Retirement Longitudinal Study (CHARLS) baseline survey of 2011. No doubt the most visible devastation of the Famine is the suffering and loss of lives as a result of severe malnutrition during the Famine. However exposure to the Famine during early childhood may scar the survivors for a long time, even for life. These long-term, less visible effects should be studied to understand the full impact of the Famine.

The Famine has a number of unique features which makes it a good case for studying the long-term effects of a famine in general. First, it was long in duration (3 years in the majority of affected provinces), widespread in scope (almost all provinces in China were affected), and devastating in its consequences (causing up to 30 million lost lives). Second, there were substantial regional variations in the Famine's impact. In particular, rural residents were much more severely affected because the government's food rationing system only provided urban residents access to sufficient food for subsistence. The intensity of the Famine 
varied across different provinces as well due to differences in natural conditions (e.g., weather, soil, etc.) and provincial governments' responses to food shortages. Moreover, the Famine's regional impact can be isolated because internal migration was prevented by the household registration system, and neither special government assistance nor international aid was received by any province affected by the Famine. In fact the government denied the occurrence of the Famine for decades. The Famine was virtually unnoticed outside of China until the release of demographic data by the Chinese government in the early 1980s. Third, since the Famine took place during a period of relative political stability, its impact was not confounded by other factors often associated with a famine, such as violent conflicts (Meng and Qian, 2007). Finally, the population cohort who experienced the Famine in utero and/or early childhood were entering or in their 50s at the time of the survey in 2011. If the Famine had any long-term health effects on the survivors, these effects would have manifested by then.

Using the difference-in-differences approach, we isolate the long-term health effects for 5 different birth-cohorts who were exposed to the Famine in different stages of their lives. We examine 3 groups of health indicators: physical health, mental health and health related life-style choices. We find that exposure to the Famine (1) reduced adult height for all cohorts; (2) had some negative impact on mental health for some cohorts; (3) had no significant effects on the risk of acquiring common chronic diseases; (4) had no consistent effects on health related lifestyle choices; and (5) had the effect of lowering the risk of being overweight for 2 out of 5 cohorts. Notably where the effects of Famine on long-term health were found to be statistically significant, the magnitudes were small. For instance, the cohort that experienced the largest height-reduction was on average $0.1 \mathrm{~cm}$ shorter. Overall it appears that while we can identify some long-term health effects of the Famine on the survivors, these effects were small. This does not detract from the enormous and tragic losses caused by the Famine, but does highlight the strength of human resilience which helped the Famine survivors enter their late adulthood relatively unscathed by the extreme adversity experienced in their early childhood.

The rest of the paper is organised as follows. Section 2 reviews the literature and outlines our contribution to it. Section 3 briefly discusses the causes, severity and regional variations of the Famine. Section 4 describes our data and empirical approach. Section 5 presents the empirical results and section 6 provides some robust tests. Section 7 concludes. 


\section{Literature review}

Widely regarded as the pioneering work on the long-term health effects of famine, Stein et al. (1975) use vital registration records to analyse the effects of acute food deprivation during the Dutch 1944-1945 famine. The study finds a sharp decline in fertility and birth weights during the famine, and an increase in premature births and perinatal deaths for mothers who were severely malnourished during the first trimester of pregnancy. However, it finds no evidence to suggest that famine exposure had any negative effect on the body size, general state of health or mental ability of the exposed cohort by the time they reached age 18 .

Later studies of the Dutch 1944-1945 famine, however, have found that individuals exposed to prenatal starvation were adversely affected later in life. For example, they had worse self-reported health status, higher risks of coronary heart disease morbidity and obesity (Roseboom et al., 2001), and were more likely to suffer from adult anti-social personality disorders (Hoek et al 1998, Neugebauer et al., 1999).

Studies of other famines have similarly identified adverse long-term health effects on the population exposed to them. For instance, Doblhammer et al. (2013) find the 1866-1868 Finnish famine increased mortality at old age. Razzaque et al.'s (1990) analysis of the Bangladesh famine of 1974-1975 also finds evidence of higher mortality in famine-born and conceived cohorts than in the cohorts not exposed to the famine.

Kesternich et al. (2015) study the hunger experience in the post-war period and find that lower-income adults who experienced hunger during childhood (ages 0-16) spent a larger fraction of income on food, and had a higher risk of obesity as adults. They suggest that an early-life event can affect subsequent behaviour and such influence on behaviour may be a mechanism through which early-childhood circumstances can have long-term health consequences.

A number of studies have explored the long-term effects of the Chinese Famine of 1959-61 on health outcomes of the affected population. Some studies have used the China Health and Nutrition Surveys (CHNS) (Luo, Mu, and Zhang 2006; Chen and Zhou, 2007; Gørgens et al., 2012). Others have used Census data (Mu and Zhang, 2008; Shi, 2011), or a combination of these and other supplementary datasets (Meng and Qian, 2009). Still others 
have taken advantage of hospital health records (St. Clair et al., 2005). Different studies tend to focus on different cohorts, and look at different aspects of the Famine's impact, including its impact on physical and mental health, and economic activities and outcomes. Evidence from these studies point to the presence of long-term adverse impact of the Famine on survivors, including height reduction, higher risks of being overweight and disabled; higher risks of developing mental disorders; and worse economic outcomes measured by education attainment, labor market participation and wealth.

For example, Chen and Zhou (2007) study different cohorts born during 1954-1962 and show that exposure to the Famine (before age 5) reduced the adult height of individuals, with the largest height reduction for the 1959 birth-cohort. This result was confirmed by Meng and Qian (2009) and Gorgens et al. (2012).

In relation to mental health, St. Clair et al. (2005) analyse psychiatric case records in a mental hospital in Anhui province and find that children born during the Famine were twice as likely to develop schizophrenia.

With respect to economic outcomes, Chen and Zhou (2007) suggest that the 1958 and 1959 birth-cohorts worked fewer hours and had lower wealth as measured by the size of residence. Meng and Qian (2009) estimate the impact on the upper quantiles of the distribution of outcomes and suggest that in utero and early childhood exposure to the Famine was associated with lower education attainment and fewer work hours.

Several studies suggest that the Famine had a greater impact on women than men. For instance, Luo, Mu, and Zhang (2006) show that only female survivals of the Famine were more likely to be overweight as adults. Mu and Zhang (2008) find that the Famine had the effect of raising the disability rate and illiteracy rate for women but not men. Similarly, Shi (2011) finds that the Famine had significant negative impact on female, but not on male survivors. Specifically, women exposed to the Famine in the first year of life were less wealthy and less likely to complete high school.

Mu and Zhang (2008) argue that much of the gender variations may be explained by differences in mortality. Female age-specific mortality rates were lower than those for men during the Famine years. Also female foetuses exposed to the Famine were more likely to 
survive than male foetuses. In fact, the Famine not only lowered the male-to-female sex ratio for the generation exposed to it but also for the second generation (Almond et al., 2007). The better adaptation by females to the Famine increases their chances of survival, but when the environment changed in adulthood, the adaptation became a disadvantage, resulting in higher risks of bad health outcomes. This is the idea of the Barker hypothesis.

This paper contributes to the existing literature in the following ways. First, it makes use of the CHARLS survey of 2011. The survey provides information on a large number of health indicators which enable us to estimate the effects of the Famine on physical health, mental health and health related life-style choices. Also the survey caught the Famine survivors as they were entering their 50s which means the estimated effects were in fact "long-term".

Second, it takes a more nuanced approach in the definition of important variables, which increases the precision of the estimated effects. For instance, it sets the Famine starting year and ending year for each province based on excess death data. This captures more fully the regional variations of Famine exposure. Also, the cohorts exposed to the Famine are defined on the basis of both the timing (in utero, $1^{\text {st }}$ year of life, 1-5 years of age) and the length (in utero only, in utero plus $1^{\text {st }}$ year of life, etc.) of their exposure. This allows us to examine possible differential effects of Famine exposure.

Third, our analysis confirms precious studies in terms of the Famine's negative effect on adult height, and provides additional results in relation to mental health and behaviour. However, we highlight the finding that while some of the Famine's long-term health effects were statistically significant, the magnitudes were small.

\section{The Chinese Famine: causes, severity and regional variations}

The Famine was largely attributable to systematic failures in the government's development strategy and its implementation through central planning (Li and Yang, 2005). In rural areas, agricultural production became progressively more collectivised in the 1950s, which severely damaged farmers' work incentive (Lin and Yang, 2000). Agricultural production fell sharply as a result. Grain output dropped 15\% in 1959 and another 15\% in 1960 (Li and Yang, 2005). The estimated availability of food energy during 1959-61 fell well below 
the average food energy requirement of about 2100 calories per person per day (Ashton et al., 1984).

At the same time, the government accelerated the industrialization process and diverted more agricultural resources to industry. In particular, the central government had in place aggressive grain procurement programs and even exported rice, leaving farmers insufficient food to sustain themselves. A nation-wide Famine broke out (Yang and Su, 1998, Li and Yang, 2005). The Famine lasted for 3 years in most provinces with some notable regional variations (discussed below).

As shown in Figure 1, the national death rate rose sharply in 1959 to $14.6 \%$, and climbed to $25.4 \%$ in 1960 before falling back to $14.2 \%$ in 1961 , still higher than the pre-famine 3-year average of $11.4 \%$. Meanwhile, birth rates dropped from $34.03 \%$ in 1957 to $29.2 \%$ in 1958 , and to the lowest level of $18.0 \%$ in 1961 . Some estimates show that the Famine led to 23-30 million excess deaths and 30 million lost births (Ashton et al., 1984; Peng, 1987).

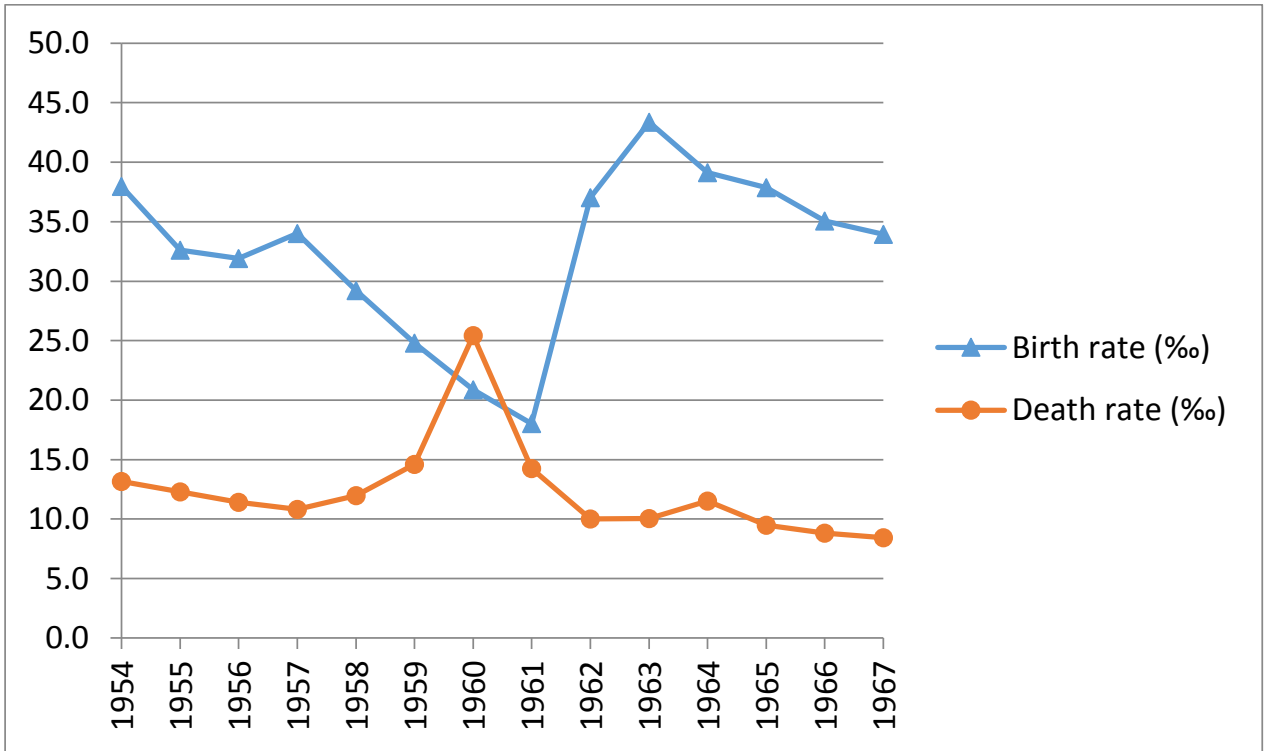

Fig Source: China National Bureau of Statistics, http://data.stats.gov.cn/easyquery.htm?cn=C01

\section{Figure 1 National death rate and birth rate}

Although the Famine is commonly referred to as the Famine of 1959-1961, the onset and the end of the Famine varied across regions. In our analysis, we time the Famine in different provinces based on provincial death rates: the first year of the Famine for a province was the year when there was a jump in death rate by more than $10 \%$ (relative to the previous 
year) in that province; the last year of the Famine for a province was the year before the death rate fell to no more than $10 \%$ higher than the 3-year average before the Famine for that province. The Famine duration for each province is shown in Table A1 in the Appendix. Based on the death rate data, there are variations in both the beginning and ending year of the Famine: the Famine started in 1958 for 8 provinces, in 1959 for 19 provinces and in 1960 for 1 province; and it ended in 1960 for 13 provinces, in 1961 for 12 provinces and in 1962 for 3 provinces. Relatedly the duration of the Famine also varied: 1 year for 1 province, 2 years for 7 provinces, 3 years for 16 provinces, 4 years for 2 provinces, and 5 years for 2 provinces (Sichuan and Chongqing).

The intensity of the Famine also varied greatly across provinces due to differences in a number of aspects, for instance, the proportion of rural population, severity of crop failure, and provincial government's responses to food shortages. We can measure the provincial variations in Famine intensity by comparing the excess death rates across provinces. Excess death rate is defined as the difference between the actual death rate and that which would have occurred under normal conditions. A simple way of calculating excess death rates, used in Chen and Zhou (2007), is to take the difference between the actual death rate in each of the Famine years and the average death rate for the 3 years before the Famine. We follow Chen and Zhou's (2007) method and calculate the excess death rates for each of the Famine years for 29 of the 31 provinces in China ${ }^{1}$. The main difference between our calculation and that in Chen and Zhou (2007) is that we allow for provincial variations in the timing of the Famine, whereas Chen and Zhou (2007) define the Famine year to be 1959 to 1961 for all provinces and their calculation only covers 8 provinces. The provincial death rates and excess death rates during the Famine years are presented in Table 1.

${ }^{1}$ Hainan and Tibet are not included in our calculation because Hainan was part of Guangdong province until 1988 and Tibet does not have official data on death rates during the Famine years. Chongqing, which was separated from Sichuan province to become a directly-administered municipality in 1997 , is nevertheless included because the relevant data for the municipality are available for the years under consideration. 
Table 1. Excess death rate by province (\%)

\begin{tabular}{|c|c|c|c|c|c|c|c|c|c|c|}
\hline & \multicolumn{7}{|c|}{ Death rate } & \multicolumn{3}{|c|}{ Excess death rate } \\
\hline & 1956 & 1957 & 1958 & 1959 & 1960 & 1961 & 1962 & 1959 & 1960 & 1961 \\
\hline Anhui & 14.25 & 9.10 & 12.36 & 16.72 & 68.58 & 8.11 & 8.23 & 4.82 & 56.68 & -3.79 \\
\hline Beijing & 7.73 & 8.19 & 8.08 & 9.66 & 9.14 & 10.80 & 8.77 & 1.66 & 1.14 & 2.80 \\
\hline Chongqing & 11.3 & 11.0 & 16.1 & 31.5 & 44.9 & 26.5 & 15.5 & 18.70 & 32.10 & 13.70 \\
\hline Fujian & 10.2 & 9.8 & 9.4 & 12.5 & 20.7 & 16.0 & 11.6 & 2.70 & 10.90 & 6.20 \\
\hline Gansu & 10.78 & 11.33 & 21.11 & 17.36 & 41.32 & 11.48 & 8.25 & 2.95 & 26.91 & -2.93 \\
\hline Guangdong $^{\mathrm{b}}$ & & 8.36 & & & & & 9.42 & & & \\
\hline Guangxi & 12.46 & 12.35 & 11.74 & 17.49 & 29.46 & 19.50 & 10.25 & 5.31 & 17.28 & 7.32 \\
\hline Guizhou & 13 & 12.4 & 15.3 & 20.3 & 52.3 & 23.3 & 11.6 & 6.73 & 38.73 & 9.73 \\
\hline He'nan & 14.0 & 11.8 & 12.7 & 14.1 & 39.6 & 10.2 & 8 & 1.27 & 26.77 & -2.63 \\
\hline Hebei & 11.3 & 11.3 & 10.9 & 12.3 & 15.8 & 13.6 & 9.1 & 1.13 & 4.63 & 2.43 \\
\hline Heilongjiang & 10.08 & 10.45 & 9.17 & 12.76 & 10.52 & 11.13 & 8.62 & 2.86 & 0.62 & 1.23 \\
\hline Hu'nan & 11.51 & 10.41 & 11.65 & 12.99 & 29.42 & 17.48 & 10.23 & 1.80 & 18.23 & 6.29 \\
\hline Hubei & 10.81 & 9.61 & 9.60 & 14.49 & 21.21 & 9.08 & 8.77 & 4.48 & 11.20 & -0.93 \\
\hline Inner Mongolia & 7.9 & 10.5 & 7.9 & 11 & 9.4 & 8.8 & 9.0 & 2.23 & 0.63 & 0.03 \\
\hline Jiangsu & 13.0 & 10.3 & 9.4 & 14.6 & 18.4 & 13.4 & 10.4 & 3.70 & 7.50 & 2.50 \\
\hline Jiangxi & 12.5 & 11.5 & 11.3 & 13.0 & 16.1 & 11.5 & 11.0 & 1.23 & 4.33 & -0.27 \\
\hline Jilin & 7.5 & 9.1 & 9.1 & 13.4 & 10.1 & 12.1 & 10.0 & 4.83 & 1.53 & 3.53 \\
\hline Liaoning & 6.6 & 9.4 & 8.8 & 11.8 & 11.5 & 17.5 & 8.5 & 3.53 & 3.23 & 9.23 \\
\hline Ningxia & 10.6 & 11.1 & 15.0 & 15.8 & 13.9 & 10.7 & 8.5 & 3.57 & 1.67 & -1.53 \\
\hline Qinghai & 9.4 & 10.4 & 13.0 & 16.6 & 40.7 & 11.7 & 5.4 & 5.67 & 29.77 & 0.77 \\
\hline Shandong & 12.10 & 12.10 & 12.80 & 18.20 & 23.60 & 18.40 & 12.40 & 5.87 & 11.27 & 6.07 \\
\hline Shanghai & 6.6 & 6.1 & 6.2 & 7.8 & 6.9 & 7.7 & 7.2 & 1.50 & 0.60 & 1.40 \\
\hline Shannxi & 9.85 & 10.31 & 11.01 & 12.72 & 12.27 & 8.76 & 9.35 & 2.33 & 1.88 & -1.63 \\
\hline shanxi & 11.6 & 12.7 & 11.7 & 12.8 & 14.2 & 12.2 & 11.3 & 0.80 & 2.20 & 0.20 \\
\hline Sichuan & 10.4 & 12.1 & 25.2 & 47.0 & 54.0 & 29.4 & 14.6 & 31.10 & 38.10 & 13.50 \\
\hline Tianjin & 8.79 & 9.35 & 8.66 & 9.88 & 10.34 & 9.89 & 7.36 & 0.95 & 1.41 & 0.96 \\
\hline Xinjiang & 14.20 & 14.00 & 13.00 & 18.84 & 15.67 & 11.71 & 9.71 & 5.11 & 1.94 & -2.02 \\
\hline Yunnan & 15.21 & 16.29 & 21.62 & 17.95 & 26.26 & 11.84 & 10.85 & 0.24 & 8.55 & -5.87 \\
\hline Zhejiang & 9.5 & 9.3 & 9.2 & 10.8 & 11.9 & 9.8 & 8.6 & 1.47 & 2.57 & 0.47 \\
\hline
\end{tabular}

From Table 1, we can detect some patterns in provincial variations of Famine intensity. First, since the urban population was guaranteed a minimum level of food supply by the grain ration system, directly-administered municipalities with a small number of rural residents, namely, Beijing, Shanghai and Tianjin had relatively low excess death rates during the Famine. Similarly, the north-eastern provinces hosting China's heavy industry bases, Helongjiang, Jilin and Liaoning, suffered lower excess deaths. Second, ironically, some of the large grain producing provinces such as Gansu, Henan, Hunan and Sichuan were among the most severely 
hit by the Famine. This is partly due to the fact that the local authorities were more cooperative with the central government and allowed large quantities of grain to be exported from these provinces during the Famine years (Lin and Yang, 2000). In contrast, with the exception of Guangxi, the traditionally poorer autonomous regions of Inner Mongolia, Ningxia and Xinjiang, experienced relatively moderate increases in death rates.

\section{Empirical approach, data and variables}

\subsection{Empirical approach}

We use the difference-in-differences (DID) approach to assess the long-term effects of the Famine on different cohorts. This allows us to exploit both regional and cohort variations in Famine exposure. Individuals living in provinces of higher Famine intensity would have suffered greater food deprivation. Famine exposure at different ages would have different effects on individuals. For instance, with in utero exposure, malnutrition of the mother can adversely affect foetal development. Exposure at very young age may be associated with both childhood malnutrition and lower quality of care from adults (Meng and Qian, 2007). In our estimations, region invariant differences between cohorts are controlled for by cross regional comparisons and cohort invariant differences between regions are controlled for by comparison across cohorts.

We divide the individuals exposed to the Famine into 5 different (and mutually exclusive) treatment cohorts: (1) cohort 1: those exposed to the Famine only in utero; (2) cohort 2: those exposed to the Famine in utero and during their first year of life; (3) cohort 3: those exposed to the Famine in utero, during their first year of life and in early childhood (1-5 years of age); (4) cohort 4: those exposed to the Famine in their first year of life and in early childhood; and (5) cohort 5: those exposed to the Famine only in early childhood. Specifically, we estimate:

$$
H_{i j k}=C+\beta_{k}+\sum_{k=1}^{5} \lambda_{k}\left(e d r_{j}\right)\left(\operatorname{cohort}_{i k}\right)+\delta e d r_{j}+X_{i} \gamma+\varepsilon_{i j k}
$$

where $H_{i j k}$ is the dependent variable in 2011 for individual $i$, born in province $j$ and belonging to cohort $k . H_{i j k}$ may be indicators of physical health, mental health and health related lifestyle choices. $\beta_{k}$ are the cohort fixed effects; cohort $_{i k}$ is a binary variable which equals 1 for 
individuals belonging to cohort $k$, and 0 otherwise; $e d r_{j}$ is the excess death rate of region $j$ in 1960, the worst year of the Famine; $X_{i}$ is a set of variables controlling for individual characteristics, including age, gender, employment and education; and $\varepsilon_{i j k}$ is the error term.

We hypothesize that individuals exposed to the Famine would have different health outcomes relative to those in similar situations but not exposed to the Famine, that is, $\lambda_{k}$ would be significantly different from zero.

\subsection{Data}

The data used in our analysis come from two sources. First, data on birth and death rates at the provincial level are obtained from China Compendium of Statistics: 1949-1985. Second, for information on individuals, we rely on the China Health and Retirement Longitudinal Study (CHARLS) baseline survey of 2011. The CHARLS 2011 survey collects a wide range of information including: demographics, family structure/transfer, health status and functioning, biomarkers, health care and insurance, work, retirement and pension, income and consumption, assets, and community. The survey was conducted by the Institute of Social Science Survey at Peking University, and covered about 10,000 households and 17,500 individuals.

From the 2011 CHARLS survey data, we select individuals born between 1953 and 1967, of which some have experienced the Famine, and others have not. We focus on individuals in our sample who lived through the Famine years in rural areas. The main reason for this is that food rationing associated with China's residence registration system largely insulated urban residents from serious food shortages. Another reason is that we want to isolate the effect of the Famine from the confounding effects of the Cultural Revolution of 1966-76 which disrupted the lives of the urban population much more than their rural counterparts ${ }^{2}$.

2 During the Cultural Revolution, the urban cohort who lived through the Famine years had their education severely interrupted and many of them were sent to countryside as laborers. 
In our analysis, we regard an individual as a rural resident during the Famine years if his/her main place of residence before 16 years of age was rural $^{3}$. As shown in Table 2, the majority of the respondents were rural residents during the Famine years. There is a very high probability that a person's main place of residence before 16 is also the place in which he/she was born and grew up. This is because until the 1990s, the residence registration system tightly restricted internal migration across provinces and between rural and urban areas within a province. Migration restrictions were harshly enforced during the Famine years. There is anecdotal evidence that hungry rural residents were stopped from leaving their villages (Chen and Zhou, 2007). This migration prohibition limited self-selection through migration and increased regional variations in Famine intensity.

Table 2. Sample distribution by birth year and type of birth place

\begin{tabular}{lcccc}
\hline & \multicolumn{2}{c}{ Rural } & \multicolumn{2}{c}{ Urban } \\
& Frequency & $\%$ & Frequency & $\%$ \\
\hline 1953 & 445 & 7.86 & 43 & 7.6 \\
1954 & 483 & 8.54 & 42 & 7.42 \\
1955 & 470 & 8.31 & 50 & 8.83 \\
1956 & 414 & 7.32 & 38 & 6.71 \\
1957 & 451 & 7.97 & 43 & 7.6 \\
1958 & 336 & 5.94 & 37 & 6.54 \\
1959 & 285 & 5.04 & 27 & 4.77 \\
1960 & 290 & 5.13 & 39 & 6.89 \\
1961 & 248 & 4.38 & 20 & 3.53 \\
1962 & 493 & 8.71 & 57 & 10.07 \\
1963 & 531 & 9.38 & 57 & 10.07 \\
1964 & 432 & 7.64 & 42 & 7.42 \\
1965 & 448 & 7.92 & 39 & 6.89 \\
1966 & 266 & 4.7 & 26 & 4.59 \\
1967 & 66 & 1.17 & 6 & 1.06 \\
Total & 5,658 & 100 & 566 & 100 \\
\hline
\end{tabular}

Table 3 shows the rural sample distribution by birth-year and birth-province. Beijing and Guangdong are not included because of no rural samples, Ningxia is also excluded because

${ }^{3}$ The survey sought information on whether the birthplace of the respondent was rural or urban, but the question was mostly left unanswered. 
it has only two observations. In our final dataset, we have 5064 observations across 26 provinces.

Table 3. Rural sample distribution by birth-year and birth-province

\begin{tabular}{|c|c|c|c|c|c|c|c|c|c|c|c|c|c|c|c|c|}
\hline \multirow{2}{*}{$\begin{array}{l}\text { Birth- } \\
\text { province }\end{array}$} & \multicolumn{16}{|c|}{ Birth-year } \\
\hline & 1953 & 1954 & 1955 & 1956 & 1957 & 1958 & 1959 & 1960 & 1961 & 1962 & 1963 & 1964 & 1965 & 1966 & 1967 & Tota \\
\hline Anhui & 22 & 19 & 18 & 23 & 15 & 8 & 6 & 7 & 11 & 26 & 30 & 16 & 19 & 13 & 1 & 234 \\
\hline Chongqing & 5 & 6 & 7 & 2 & 2 & 3 & 0 & 2 & 1 & 7 & 7 & 4 & 3 & 0 & 1 & 50 \\
\hline Fujian & 14 & 13 & 13 & 19 & 13 & 25 & 17 & 12 & 12 & 26 & 11 & 7 & 20 & 9 & 3 & 214 \\
\hline Gansu & 11 & 6 & 13 & 8 & 11 & 12 & 4 & 6 & 1 & 15 & 14 & 21 & 14 & 4 & 7 & 147 \\
\hline Guangxi & 17 & 17 & 20 & 12 & 11 & 13 & 7 & 8 & 9 & 18 & 16 & 8 & 10 & 7 & 1 & 174 \\
\hline Guizhou & 4 & 10 & 8 & 4 & 4 & 3 & 2 & 1 & 3 & 6 & 3 & 4 & 4 & 2 & 0 & 58 \\
\hline Henan & 34 & 40 & 31 & 40 & 36 & 23 & 30 & 17 & 22 & 43 & 61 & 43 & 53 & 25 & 5 & 503 \\
\hline Hebei & 28 & 23 & 18 & 26 & 14 & 17 & 16 & 16 & 13 & 24 & 23 & 17 & 21 & 11 & 4 & 271 \\
\hline Heilongjiang & 3 & 3 & 5 & 2 & 2 & 5 & 4 & 2 & 0 & 8 & 4 & 2 & 3 & 2 & 0 & 45 \\
\hline Hunan & 19 & 17 & 15 & 17 & 23 & 19 & 10 & 8 & 5 & 24 & 23 & 20 & 20 & 6 & 3 & 229 \\
\hline Hubei & 13 & 19 & 11 & 17 & 17 & 16 & 11 & 8 & 11 & 22 & 18 & 13 & 17 & 13 & 6 & 212 \\
\hline $\begin{array}{l}\text { Inner } \\
\text { Mongolia }\end{array}$ & 9 & 21 & 7 & 8 & 12 & 17 & 14 & 13 & 8 & 14 & 17 & 18 & 12 & 8 & 4 & 182 \\
\hline Jiangsu & 32 & 24 & 27 & 14 & 19 & 20 & 16 & 11 & 5 & 15 & 18 & 27 & 14 & 14 & 2 & 258 \\
\hline Jiangxi & 22 & 22 & 12 & 20 & 23 & 16 & 16 & 13 & 9 & 11 & 25 & 14 & 19 & 10 & 6 & 238 \\
\hline Jilin & 4 & 14 & 13 & 6 & 16 & 5 & 4 & 1 & 1 & 8 & 9 & 4 & 4 & 7 & 2 & 98 \\
\hline Liaoning & 9 & 9 & 16 & 11 & 22 & 10 & 13 & 13 & 6 & 13 & 12 & 13 & 6 & 2 & 2 & 157 \\
\hline Qinghai & 10 & 8 & 9 & 4 & 4 & 6 & 6 & 10 & 7 & 11 & 6 & 11 & 5 & 3 & 1 & 101 \\
\hline Shandong & 36 & 30 & 44 & 35 & 50 & 25 & 20 & 26 & 22 & 30 & 41 & 43 & 39 & 25 & 5 & 471 \\
\hline Shanghai & 0 & 0 & 1 & 0 & 1 & 2 & 0 & 1 & 0 & 0 & 0 & 0 & 0 & 0 & 0 & 5 \\
\hline Shannxi & 13 & 13 & 8 & 19 & 14 & 9 & 8 & 9 & 9 & 22 & 22 & 19 & 19 & 14 & 5 & 203 \\
\hline Shanxi & 15 & 16 & 11 & 10 & 12 & 13 & 11 & 18 & 14 & 11 & 20 & 16 & 14 & 10 & 1 & 192 \\
\hline Sichuan & 45 & 29 & 49 & 31 & 16 & 24 & 17 & 12 & 21 & 30 & 45 & 24 & 44 & 21 & 7 & 415 \\
\hline Tianjin & 2 & 3 & 1 & 5 & 6 & 5 & 9 & 4 & 4 & 5 & 11 & 4 & 2 & 4 & 2 & 67 \\
\hline Xinjiang & 3 & 5 & 6 & 0 & 5 & 1 & 2 & 4 & 2 & 2 & 1 & 2 & 1 & 2 & 0 & 36 \\
\hline Yunnan & 23 & 29 & 28 & 24 & 36 & 24 & 12 & 18 & 20 & 28 & 37 & 35 & 43 & 16 & 3 & 376 \\
\hline Zhejiang & 8 & 7 & 11 & 12 & 12 & 5 & 4 & 9 & 8 & 10 & 11 & 14 & 10 & 5 & 2 & 128 \\
\hline Total & 401 & 403 & 402 & 369 & 396 & 326 & 259 & 249 & 224 & 429 & 485 & 399 & 416 & 233 & 73 & 5064 \\
\hline
\end{tabular}

\subsection{Variables}

The definitions of the variables are shown in Table A2. We explain some of the variables further below.

We study how exposure to the Famine in early life may have long-term effects on health outcomes and life-style choices. The health outcome measures include: height in centimetres 
(height); whether a person was overweight (overweight), had diabetes (diabetes), had hypertension (hypertension), had at least one of the following chronic diseases: cancer, liver diseases, lung diseases, heart problems, stroke, kidney diseases, and stomach diseases (chronic diseases). A person with a $\mathrm{BMI} \geq 25$ is regarded as being overweight. ${ }^{4}$

We also look at mental health measured by: how often a person felt depressed (depressed), hopeful about the future (hopeful), happy (happy), and lonely (lonely), and that he/she could not continue with life as it is (cannot continue life); to what extent a person felt unsatisfied with life as a whole (unsatisfied with life).

The life-choice variables include: if a person has ever chewed tobacco, smoked a pipe or cigarettes (smoking), drank alcohol more than once a month in the past year (alcohol), if an individual exercised continuously for at least 10 minutes in a usual week (exercise), and hours per day an individual spent on household agricultural work (household agricultural work).

As explained earlier, provincial variations in Famine intensity is measured by excess death rates in 1960 ( $E d r 1960)$, the worst year of the Famine for all provinces in our sample. For our difference-in-differences estimations, we define 5 treatment cohorts based on the individuals' birth-month and birth-year': (1) Cohort 1, the cohort exposed to the Famine only in utero; (2) Cohort 2, the cohort exposed to the Famine in utero and during their first year of life; (3) Cohort 3, the cohort exposed to the Famine in utero, during their first year of life and in early childhood (1-5 years of age); (4) Cohort 4: the cohort exposed to the Famine in their first year of life and in early childhood; and (5) Cohort 5: the cohort exposed to the Famine only in early childhood.

The summary statistics of the variables in our analysis are presented in Table 4.

${ }^{4} \mathrm{BMI}$ is calculated by dividing your weight in kilograms by your height in meters squared. According to the World Health Organization classification, an adult is underweight if $\mathrm{BMI}<18.5$; overweight if $\mathrm{BMI} \geq 25$; and obese if BMI $\geq 30$ (see: http://apps.who.int/bmi/index.jsp?introPage=intro_3.html).

${ }^{5}$ Since we do not have death rate data to determine the month in which the Famine began or ended, we follow the existing literature and assume that the Famine started in January and ended in December. 
Table 4. Summary statistics

\begin{tabular}{|c|c|c|c|c|c|}
\hline Variables & Observations & Mean & Standard deviation & Minimum & Maximum \\
\hline Height & 5,064 & 159.1 & 8.230 & 108.4 & 186.5 \\
\hline Overweight & 5,064 & 0.342 & 0.474 & 0 & 1 \\
\hline Hypertension & 5,064 & 0.172 & 0.377 & 0 & 1 \\
\hline Diabetes & 5,064 & 0.0403 & 0.197 & 0 & 1 \\
\hline Chronic diseases & 5,064 & 0.418 & 0.493 & 0 & 1 \\
\hline Depressed & 4,982 & 2.007 & 1.076 & 1 & 4 \\
\hline Hopeful & 4,921 & 2.903 & 1.191 & 1 & 4 \\
\hline Happy & 5,011 & 2.934 & 1.107 & 1 & 4 \\
\hline Lonely & 5,000 & 1.510 & 0.923 & 1 & 4 \\
\hline Cannot continue life & 4,995 & 1.343 & 0.773 & 1 & 4 \\
\hline Unsatisfied with life & 4,613 & 2.990 & 0.711 & 1 & 5 \\
\hline Smoking & 5,064 & 0.373 & 0.484 & 0 & 1 \\
\hline Alcohol & 5,064 & 0.260 & 0.439 & 0 & 1 \\
\hline Exercise & 2,158 & 0.332 & 0.471 & 0 & 1 \\
\hline $\begin{array}{l}\text { Household agricultural } \\
\text { work }\end{array}$ & 3,343 & 7.370 & 2.691 & 0 & 24 \\
\hline Age & 5,064 & 51.53 & 4.189 & 44 & 58 \\
\hline Gender & 5,064 & 0.442 & 0.497 & 0 & 1 \\
\hline No schooling & 5,064 & 0.232 & 0.422 & 0 & 1 \\
\hline Primary education & 5,064 & 0.391 & 0.488 & 0 & 1 \\
\hline $\begin{array}{l}\text { Middle or higher } \\
\text { education }\end{array}$ & 5,064 & 0.377 & 0.485 & 0 & 1 \\
\hline Employment & 5,064 & 0.280 & 0.449 & 0 & 1 \\
\hline $\mathrm{C} 1:$ in utero & 5,064 & 0.0478 & 0.213 & 0 & 1 \\
\hline $\mathrm{C} 2$ : in utero $+1^{\text {st }}$ year & 5,064 & 0.0519 & 0.222 & 0 & 1 \\
\hline $\begin{array}{l}\text { C3: in utero }+1^{\text {st }} \text { year } \\
+1-5 \text { years }\end{array}$ & 5,064 & 0.0875 & 0.283 & 0 & 1 \\
\hline$C 4: 1^{\text {st }}$ year $+1-5$ years & 5,064 & 0.0646 & 0.246 & 0 & 1 \\
\hline C5: $1-5$ years & 5,064 & 0.324 & 0.468 & 0 & 1 \\
\hline
\end{tabular}

\section{Empirical Results}

Our estimation results are obtained using the probit model (if the dependent variable is binary) or the ordered probit model (if the dependent variable is ordinal). As we are interested in the long-term effects of the Famine, we report the marginal effects of Famine exposure on physical health, mental health and health related life-style choices. 


\subsection{Physical health}

Height

For all cohorts, exposure to the Famine reduced their heights (see Table 5). The estimates are statistically significant at $1 \%$ for Cohorts 3, 4 and 5; at 5\% level for Cohort 2, and at $10 \%$ level for Cohort 1 . The largest height reduction (of $-0.113 \mathrm{~cm}$ ) was experienced by Cohort 4 (exposed to the Famine during their first year of life and between 1-5 years of age). Cohort 3 which had the longest exposure to the Famine (in utero, $1^{\text {st }}$ year and between age 15) had the second largest height reduction at $0.091 \mathrm{~cm}$.

Table 5. Long-term marginal effects of the Famine on physical health

\begin{tabular}{|c|c|c|c|c|c|}
\hline Variables & Height & Overweight & Diabetes & $\begin{array}{l}\text { Chronic } \\
\text { diseases }\end{array}$ & Hypertension \\
\hline \multirow[t]{2}{*}{ Edr1960 x c1: in utero } & $-0.0509 *$ & $-0.00374 *$ & -0.000691 & -0.000884 & $-0.00467 * *$ \\
\hline & $(0.0268)$ & $(0.00208)$ & $(0.000962)$ & $(0.00221)$ & $(0.00210)$ \\
\hline \multirow{2}{*}{ Edr1960 x c2 in utero $+1^{\text {st }}$ year } & $-0.0607 * *$ & -0.00149 & -0.000432 & -0.000709 & 0.00171 \\
\hline & $(0.0257)$ & $(0.00197)$ & $(0.00115)$ & $(0.00209)$ & $(0.00181)$ \\
\hline \multirow{2}{*}{$\begin{array}{l}\text { Edr1960 x c3 in utero }+1^{\text {st }} \text { year }+ \\
1-5 \text { years }\end{array}$} & $-0.0906 * * *$ & -0.00105 & 0.000109 & 0.00103 & -0.00205 \\
\hline & $(0.0202)$ & $(0.00158)$ & $(0.000641)$ & $(0.00165)$ & $(0.00150)$ \\
\hline \multirow[t]{2}{*}{ Edr1960 x c4: $1^{\text {st }}$ year $+1-5$ years } & $-0.113 * * *$ & 0.00154 & 0.00104 & -0.000866 & 0.000799 \\
\hline & $(0.0247)$ & $(0.00191)$ & $(0.000654)$ & $(0.00201)$ & $(0.00167)$ \\
\hline \multirow[t]{2}{*}{ Edr1960 x c5: $1-5$ years } & $-0.0593 * * *$ & $-0.00269 * * *$ & $4.63 \mathrm{e}-05$ & -0.00123 & -0.00141 \\
\hline & $(0.0127)$ & $(0.00102)$ & $(0.000438)$ & $(0.00105)$ & $(0.000917)$ \\
\hline \multirow[t]{2}{*}{ c1: in utero } & 0.608 & 0.0480 & 0.0173 & -0.0232 & $0.0807 *$ \\
\hline & $(0.609)$ & $(0.0466)$ & $(0.0185)$ & $(0.0503)$ & $(0.0419)$ \\
\hline \multirow[t]{2}{*}{$\mathrm{c} 2$ in utero $+1^{\text {st }}$ year } & 0.499 & 0.0444 & -0.0177 & 0.0187 & -0.0343 \\
\hline & $(0.573)$ & $(0.0440)$ & $(0.0216)$ & $(0.0470)$ & $(0.0409)$ \\
\hline \multirow[t]{2}{*}{ c3 in utero $+1^{\text {st }}$ year $+1-5$ years } & 0.145 & -0.0248 & -0.00417 & -0.0471 & 0.0182 \\
\hline & $(0.478)$ & $(0.0378)$ & $(0.0148)$ & $(0.0399)$ & $(0.0337)$ \\
\hline \multirow[t]{2}{*}{ c4: $1^{\text {st }}$ year $+1-5$ years } & 0.541 & -0.0646 & -0.00938 & 0.0523 & 0.0191 \\
\hline & $(0.507)$ & $(0.0410)$ & $(0.0152)$ & $(0.0422)$ & $(0.0349)$ \\
\hline \multirow[t]{2}{*}{ c5: $1-5$ years } & $-0.526^{*}$ & 0.00705 & $-0.0193 *$ & 0.0148 & 0.0184 \\
\hline & $(0.289)$ & $(0.0270)$ & $(0.0104)$ & $(0.0282)$ & $(0.0233)$ \\
\hline \multirow[t]{2}{*}{ Edr1960 } & $-0.0218 * *$ & 0.000613 & -0.000243 & $0.00137^{*}$ & -0.000695 \\
\hline & $(0.00865)$ & $(0.000665)$ & $(0.000310)$ & $(0.000712)$ & $(0.000639)$ \\
\hline \multirow[t]{2}{*}{ Age } & & -0.00268 & $0.00332 * * *$ & $0.00456^{*}$ & $0.00852 * * *$ \\
\hline & & $(0.00247)$ & $(0.000936)$ & $(0.00259)$ & $(0.00216)$ \\
\hline \multirow[t]{2}{*}{ Gender } & $11.06 * * *$ & $-0.139 * * *$ & $-0.0200 * * *$ & $-0.0326 * *$ & 0.0162 \\
\hline & $(0.171)$ & $(0.0145)$ & $(0.00642)$ & $(0.0155)$ & $(0.0132)$ \\
\hline \multirow[t]{2}{*}{ Employment } & & $0.0338 * *$ & -0.000815 & $-0.0449 * * *$ & $-0.0277 * *$ \\
\hline & & $(0.0153)$ & $(0.00666)$ & $(0.0161)$ & $(0.0139)$ \\
\hline \multirow[t]{2}{*}{ Primary education } & & 0.00262 & 0.000783 & $0.0548 * * *$ & -0.0142 \\
\hline & & $(0.0181)$ & $(0.00724)$ & $(0.0190)$ & $(0.0162)$ \\
\hline \multirow[t]{2}{*}{ Middle or higher education } & & $0.0439 * *$ & 0.000124 & 0.0112 & -0.00486 \\
\hline & & $(0.0193)$ & $(0.00793)$ & $(0.0204)$ & $(0.0173)$ \\
\hline Observations & 5,064 & 5,064 & 5,064 & 5,064 & 5,064 \\
\hline
\end{tabular}

Notes: Standard errors are in parentheses. $* * *, * *, *$ indicate statistical significance at $1 \%, 5 \%$ and $10 \%$ levels, respectively. 
It is somewhat surprising that that the cohort with the longest exposure to the Famine did not experience the biggest height reduction. This may be in part due to positive selection: those women who fell pregnant during the Famine (i.e., the child had in utero exposure to the Famine) might on average be healthier than those who fell pregnant before the Famine.

\section{Overweight}

For Cohort 1 (exposed to the Famine only in utero), there was a $0.37 \%$ less chance of becoming overweight (significant at $10 \%$ level). For Cohort 5 (exposed to the Famine only between age 1-5), there was a $0.27 \%$ less chance of becoming overweight (significant at $1 \%$ ) level.

It is not clear how exposure to the Famine might affect the probability of being overweight. Kesternich et al. (2015) suggest that early-life malnutrition (in post-war Germany) had an effect of increasing people's share of food expenditure in total income, which contributed to a higher risk of obesity in adulthood. Our result contradicts their finding, but we follow their lead to see whether there is a behaviour channel through which early life trauma may have a long-term impact. We find that individuals in Cohort 5 were more likely to engage in physical activities (see Table 8). However, we see no significant beneficial behaviour effects for Cohort 1. In fact, we discover that individuals in Cohort 1 were more likely to consume alcohol.

\section{Other physical health indicators}

We also examine 3 other physical health indicators: diabetes, chronic diseases and hypertension. We find no significant negative impact of Famine exposure on these indicators. Instead, our result reveals a $0.47 \%$ reduction in the probability of hypertension for individuals in Cohort 1 (significant at 5\% level).

\section{Gender, age, employment and education effects}

We note that other things equal, males were on average 11.1 centimetres taller, and were $13.9 \%$ less likely to be overweight, $2.0 \%$ less likely to have diabetes and $3.3 \%$ less likely 
to have chronic diseases. There were no significant gender differences in the risk of hypertension.

Unsurprisingly, health risks increased with age. In particular, with a one-year increase in age, a person had $0.33 \%$ higher risk for diabetes, $0.46 \%$ higher risk for chronic diseases, and $0.85 \%$ higher risk for hypertension.

The estimated coefficients for employment and education tell us how these variables correlate with physical health. Employed individuals were $3.4 \%$ more likely to be overweight. They were $4.5 \%$ less likely to have chronic diseases and $2.8 \%$ less likely to have hypertension. Relative to individuals with no schooling, individuals with primary education were $5.5 \%$ more likely to have chronic diseases, and individuals with middle or high school education were $4.4 \%$ more likely to be overweight.

\subsection{Mental health}

We study the effect of early life exposure to the Famine on a number of mental health markers, namely, how often a person felt depressed, hopeful, happy, lonely, and despair (cannot continue life). We also look at the extent to which a person felt unsatisfied with life in general. Our results (see Table 6) show that for individuals in Cohort 4 (who experienced the Famine in their $1^{\text {st }}$ year of life and between 1-5 years of age), there was a higher risk of not feeling hopeful (significant at 5\% level). In particular, these individuals had $0.28 \%, 0.08 \%$ and $0.03 \%$ higher probabilities to feel hopeful none of the time (hopeful $=1$ ), little of the time (hopeful= 2 ), and occasionally (hopeful $=3$ ), respectively. And they had a $0.38 \%$ lower probability of feeling hopeful most of the time (hopeful $=4$ ). 
Table 6. Long-term marginal effects of the Famine on mental health

\begin{tabular}{|c|c|c|c|c|c|c|c|}
\hline Variables & & Depressed & Hopeful & Happy & Lonely & $\begin{array}{c}\text { Cannot } \\
\text { continue life }\end{array}$ & $\begin{array}{l}\text { Unsatisfied } \\
\text { with life }\end{array}$ \\
\hline \multirow{9}{*}{$\begin{array}{l}\text { Edr1960 x } \\
\text { c1: in utero }\end{array}$} & \multirow[t]{2}{*}{1} & -0.00111 & 0.00131 & 0.00152 & -0.000843 & -0.000721 & -0.000194 \\
\hline & & (0.00190) & $(0.00143)$ & $(0.00121)$ & $(0.00185)$ & (0.00183) & $(0.000186)$ \\
\hline & \multirow[t]{2}{*}{2} & 0.000103 & 0.000386 & 0.000670 & 0.000232 & 0.000266 & -0.00128 \\
\hline & & $(0.000177)$ & $(0.000421)$ & $(0.000537)$ & $(0.000510)$ & $(0.000677)$ & $(0.00122)$ \\
\hline & \multirow[t]{2}{*}{3} & 0.000409 & 0.000124 & 0.000203 & 0.000273 & 0.000219 & 0.000102 \\
\hline & & (0.000701) & $(0.000136)$ & $(0.000165)$ & $(0.000601)$ & $(0.000557)$ & $(0.000106)$ \\
\hline & \multirow[t]{2}{*}{4} & 0.000596 & -0.00182 & -0.00239 & 0.000338 & 0.000236 & 0.00105 \\
\hline & & $(0.00102)$ & (0.00199) & $(0.00191)$ & $(0.000744)$ & (0.000599) & (0.00100) \\
\hline & 5 & & & & & & $\begin{array}{c}0.000321 \\
(0.000307)\end{array}$ \\
\hline \multirow{9}{*}{$\begin{array}{l}\text { Edr1960 x } \\
\text { c2: in utero + } \\
1^{\text {st }} \text { year }\end{array}$} & \multirow[t]{2}{*}{1} & 0.000159 & 0.000524 & $-5.55 e-05$ & -0.00226 & $1.61 \mathrm{e}-05$ & -0.000250 \\
\hline & & $(0.00188)$ & $(0.00136)$ & $(0.00116)$ & (0.00186) & (0.00166) & $(0.000183)$ \\
\hline & \multirow[t]{2}{*}{2} & $-1.47 e-05$ & 0.000154 & $-2.45 e-05$ & 0.000621 & $-5.94 e-06$ & -0.00165 \\
\hline & & $(0.000175)$ & $(0.000401)$ & $(0.000512)$ & $(0.000511)$ & $(0.000612)$ & $(0.00120)$ \\
\hline & \multirow[t]{2}{*}{3} & $-5.85 e-05$ & $4.95 \mathrm{e}-05$ & $-7.44 \mathrm{e}-06$ & 0.000732 & $-4.88 \mathrm{e}-06$ & 0.000132 \\
\hline & & (0.000695) & (0.000129) & $(0.000155)$ & $(0.000603)$ & $(0.000503)$ & (0.000109) \\
\hline & \multirow[t]{2}{*}{4} & $-8.52 \mathrm{e}-05$ & -0.000727 & $8.74 \mathrm{e}-05$ & 0.000907 & $-5.25 e-06$ & 0.00136 \\
\hline & & $(0.00101)$ & (0.00189) & $(0.00183)$ & $(0.000747)$ & $(0.000541)$ & $(0.000982)$ \\
\hline & 5 & & & & & & $\begin{array}{c}0.000415 \\
(0.000302)\end{array}$ \\
\hline \multirow{9}{*}{$\begin{array}{l}\text { Edr } 1960 \mathrm{x} \\
\text { c3: in utero + } \\
1^{\text {st }} \text { year }+1-5 \\
\text { years }\end{array}$} & \multirow[t]{2}{*}{1} & -0.000874 & -0.000794 & 0.00106 & 0.000619 & -0.00168 & $-0.000246^{*}$ \\
\hline & & $(0.00145)$ & $(0.00107)$ & (0.000908) & $(0.00143)$ & $(0.00121)$ & $(0.000146)$ \\
\hline & \multirow[t]{2}{*}{2} & $8.13 \mathrm{e}-05$ & -0.000233 & 0.000466 & -0.000170 & 0.000619 & $-0.00163^{*}$ \\
\hline & & (0.000135) & $(0.000313)$ & $(0.000401)$ & (0.000393) & $(0.000448)$ & $(0.000948)$ \\
\hline & \multirow[t]{2}{*}{3} & 0.000323 & $-7.50 \mathrm{e}-05$ & 0.000141 & -0.000200 & 0.000509 & 0.000129 \\
\hline & & (0.000536) & $(0.000101)$ & $(0.000123)$ & $(0.000463)$ & (0.000369) & $(9.18 \mathrm{e}-05)$ \\
\hline & \multirow[t]{2}{*}{4} & 0.000470 & 0.00110 & -0.00166 & -0.000248 & 0.000548 & $0.00133^{*}$ \\
\hline & & (0.000780) & $(0.00148)$ & $(0.00143)$ & (0.000574) & (0.000397) & $(0.000778)$ \\
\hline & 5 & & & & & & $\begin{array}{l}0.000408^{*} \\
(0.000240)\end{array}$ \\
\hline \multirow{10}{*}{$\begin{array}{l}\text { Edr } 1960 \text { x } \\
\text { c4: } 1^{\text {st }} \text { year }+ \\
1-5 \text { years }\end{array}$} & \multirow[t]{2}{*}{1} & 0.00191 & $0.00277 * *$ & -0.000902 & 0.000706 & 0.00198 & -0.000165 \\
\hline & & $(0.00178)$ & $(0.00135)$ & $(0.00111)$ & $(0.00173)$ & $(0.00165)$ & $(0.000176)$ \\
\hline & \multirow[t]{2}{*}{2} & -0.000178 & $0.000813^{* *}$ & -0.000399 & -0.000194 & -0.000730 & -0.00109 \\
\hline & & (0.000167) & $(0.000398)$ & $(0.000491)$ & $(0.000475)$ & $(0.000610)$ & (0.00116) \\
\hline & 3 & -0.000705 & $0.000261 * *$ & -0.000121 & -0.000229 & -0.000600 & $8.67 \mathrm{e}-05$ \\
\hline & & (0.000658) & $(0.000131)$ & $(0.000150)$ & $(0.000560)$ & $(0.000502)$ & $(9.86 \mathrm{e}-05)$ \\
\hline & 4 & -0.00103 & $-0.00384 * *$ & 0.00142 & -0.000283 & -0.000645 & 0.000894 \\
\hline & & (0.000958) & $(0.00188)$ & $(0.00175)$ & (0.000694) & $(0.000540)$ & $(0.000950)$ \\
\hline & 5 & & & & & & 0.000273 \\
\hline & & & & & & & $(0.000291)$ \\
\hline Edr1960 x & 1 & $6.63 \mathrm{e}-05$ & $3.38 \mathrm{e}-05$ & 0.000804 & $-1.40 \mathrm{e}-06$ & -0.000861 & -0.000152 \\
\hline c5: $1-5$ years & & $(0.000931)$ & $(0.000692)$ & $(0.000581)$ & (0.000894) & $(0.000821)$ & $(9.25 \mathrm{e}-05)$ \\
\hline & 2 & $-6.17 e-06$ & $9.92 \mathrm{e}-06$ & 0.000355 & $3.85 \mathrm{e}-07$ & 0.000318 & $-0.00101 *$ \\
\hline & & $(8.66 \mathrm{e}-05)$ & (0.000203) & (0.000257) & $(0.000246)$ & $(0.000303)$ & $(0.000602)$ \\
\hline & 3 & $-2.45 e-05$ & $3.19 \mathrm{e}-06$ & 0.000108 & $4.54 \mathrm{e}-07$ & 0.000262 & $8.01 \mathrm{e}-05$ \\
\hline & & (0.000344) & $(6.53 \mathrm{e}-05)$ & $(7.92 \mathrm{e}-05)$ & $(0.000290)$ & $(0.000250)$ & $(5.79 \mathrm{e}-05)$ \\
\hline & 4 & $-3.57 e-05$ & $-4.69 e-05$ & -0.00127 & $5.62 \mathrm{e}-07$ & 0.000281 & $0.000826 *$ \\
\hline & & $(0.000501)$ & $(0.000960)$ & $(0.000916)$ & $(0.000359)$ & (0.000269) & $(0.000494)$ \\
\hline & 5 & & & & & & $\begin{array}{l}0.000253 * \\
(0.000152)\end{array}$ \\
\hline Ohservatio & & 4982 & 4921 & 5011 & 5000 & 4995 & 4613 \\
\hline
\end{tabular}

Notes: For the first 5 estimations, the categories refer to the frequency of the mental states in the past week: $=1$ Rarely or none of the time; $=2$ Some or little of the time $(<1$ day); =3 Occasionally or a moderate amount of the time $(3-4$ days $) ;=4$ 
Most or all of the time (5-7 days). For the last estimation "Unsatisfied with life", =1 completely satisfied; =2 very satisfied; $=3$ somewhat satisfied; $=4$ not very satisfied; $=5$ not at all satisfied.

Also individuals in Cohort 3 and Cohort 5 were more likely to feel unsatisfied with life (significant at $10 \%$ level). Specifically, individuals in cohort 3 were $0.02 \%$ and $0.16 \%$ less likely to be "completely satisfied" (unsatisfied with life $=1$ ) and "very satisfied" with life (unsatisfied with life $=2$ ), respectively. At the same time, they were $0.13 \%$ and $0.04 \%$ more likely to be "not very satisfied" (unsatisfied with life $=4$ ) and "not at all satisfied" with life (unsatisfied with life $=5$ ), respectively. Individuals in Cohort 5 were $0.10 \%$ less likely to be "very satisfied" with life. And they were $0.08 \%$ and $0.02 \%$ more likely to be "not very satisfied" and "not at all satisfied" with life, respectively.

Overall, we have detected statistically significant negative impact of the Famine on mental health. However the magnitudes of the estimated average marginal effects were quite small. It appears therefore exposure to the Famine did have substantial long-term negative effect on mental health.

\subsection{Health related lifestyle choices}

We explore health related lifestyle choices as a potential pathway for early life events to exert long-term influence. As shown in Table 7, we find that Cohort 1 had a $0.29 \%$ higher probability of consuming alcohol (significant at $10 \%$ level), and that Cohort 5 had a $0.45 \%$ higher probability of exercising regularly.

Table 7. Long-term marginal effects of the Famine on health related lifestyle choices

\begin{tabular}{lcccc}
\hline Variables & Smoking & Alcohol & Exercise & $\begin{array}{c}\text { Household } \\
\text { agricultural work }\end{array}$ \\
\hline Edr1960 x c1: in utero & 0.00228 & $0.00288^{*}$ & 0.000283 & -0.00164 \\
& $(0.00151)$ & $(0.00163)$ & $(0.00297)$ & $(0.0146)$ \\
Edr1960 x c2 in utero + $1^{\text {st }}$ year & 0.000948 & -0.000823 & -0.000251 & 0.000101 \\
& $(0.00144)$ & $(0.00162)$ & $(0.00289)$ & $(0.0139)$ \\
Edr1960 x c3 in utero + 1 ${ }^{\text {st }}$ year + & -0.000635 & -0.00128 & 0.00155 & -0.00690 \\
$1-5$ years & $(0.00110)$ & $(0.00121)$ & $(0.00234)$ & $(0.0110)$ \\
& & & & \\
Edr1960 x c4: $1^{\text {st } y e a r+1-5 ~ y e a r s ~}$ & 0.00181 & -0.00118 & -0.000734 & -0.0184 \\
& $(0.00138)$ & $(0.00153)$ & $(0.00299)$ & $(0.0128)$ \\
Edr1960 x c5: 1-5 years & 0.000271 & $2.21 \mathrm{e}-05$ & $0.00446^{* * *}$ & -0.00171 \\
& $(0.000704)$ & $(0.000787)$ & $(0.00150)$ & $(0.00693)$ \\
Edr1960 & $-0.00109 * *$ & $0.00139 * * *$ & 0.00123 & 0.00488 \\
Observations & $(0.000481)$ & $(0.000537)$ & $(0.000997)$ & $(0.00481)$ \\
\hline
\end{tabular}


Again, while we have detected that the Famine had some statistically significant effects on health related lifestyle choices for some cohorts, the magnitudes were quite small. It is therefore reasonable to conclude that the Famine did not seem to have had a notable long-term influence on individuals' health related lifestyle choices.

\section{Further tests}

We perform 2 further sets of estimations to examine whether the empirical results presented above are robust: (1) regrouping the treatment cohorts; and (2) quantile analysis.

\subsection{Three treatment cohorts}

As an alternative to grouping the individuals exposed to the Famine into 5 cohorts, we group them into 3 cohorts: cohort 1a is the same as cohort 1 which includes individuals who experienced the Famine in utero only. Cohort 2a combines cohort 2 and 3, and includes individuals who experienced the Famine both in utero and in early childhood. Cohort 3a combines cohort 4 and 5, and includes individuals who only experienced the Famine in early childhood (0-5 years of age).

This alternative grouping emphasizes the distinction between in utero exposure and

early childhood exposure, whereas the 5-cohort grouping also attempts to differentiate exposure in the $1^{\text {st }}$ year of life versus later years (1-5 years of age).

We estimate the effects of the Famine exposure on physical health, mental health and health related lifestyle choices for these 3 cohorts. The results are presented in Table 8. Since the estimations are based on simple regrouping the treatment cohorts, we do not expect the results to be very different from our main results. 
Table 8. Long-term marginal effects of the Famine: 3 cohorts

a. Physical health

\begin{tabular}{lccccc}
\hline Variables & Height & Overweight & Diabetes & Chronic diseases & Hypertension \\
\hline Edr1960 x c1a: in utero & $-0.0509^{*}$ & $-0.00375^{*}$ & -0.000680 & -0.000873 & $-0.00467 * *$ \\
& $(0.0268)$ & $(0.00209)$ & $(0.000966)$ & $(0.00221)$ & $(0.00210)$ \\
Edr1960 x c2a: in utero & $-0.0808^{* * *}$ & -0.00110 & $-9.02 \mathrm{e}-06$ & 0.000220 & -0.000654 \\
$+0-5$ years & $(0.0166)$ & $(0.00129)$ & $(0.000577)$ & $(0.00136)$ & $(0.00121)$ \\
Edr1960 x c3a: 0-5 years & $-0.0673 * * *$ & $-0.00213 * *$ & 0.000287 & -0.00119 & -0.00110 \\
& $(0.0123)$ & $(0.000976)$ & $(0.000414)$ & $(0.00101)$ & $(0.000886)$ \\
Observations & 5,064 & 5,064 & 5,064 & 5,064 & 5,064 \\
\hline
\end{tabular}

b. Mental health

\begin{tabular}{|c|c|c|c|c|c|c|c|}
\hline Variables & & Depressed & Hopeful & Happy & Lonely & $\begin{array}{l}\text { Cannot } \\
\text { continue life }\end{array}$ & $\begin{array}{l}\text { Unsatisfied } \\
\text { with life }\end{array}$ \\
\hline $\begin{array}{l}\text { Edr1960 x } \\
\text { c1a: in } \\
\text { utero }\end{array}$ & $\begin{array}{l}4 \\
5\end{array}$ & $\begin{array}{l}-0.00113 \\
(0.00190) \\
0.000105 \\
(0.000177) \\
0.000417 \\
(0.000701) \\
0.000607 \\
(0.00102)\end{array}$ & $\begin{array}{l}0.00132 \\
(0.00143) \\
0.000387 \\
(0.000421) \\
0.000124 \\
(0.000136) \\
-0.00183 \\
(0.00199)\end{array}$ & $\begin{array}{l}0.00152 \\
(0.00122) \\
0.000672 \\
(0.000537) \\
0.000203 \\
(0.000165) \\
-0.00240 \\
(0.00192)\end{array}$ & $\begin{array}{l}-0.000839 \\
(0.00186) \\
0.000231 \\
(0.000510) \\
0.000272 \\
(0.000601) \\
0.000337 \\
(0.000745)\end{array}$ & $\begin{array}{l}-0.000723 \\
(0.00183) \\
0.000267 \\
(0.000678) \\
0.000220 \\
(0.000558) \\
0.000236 \\
(0.000599)\end{array}$ & $\begin{array}{l}-0.000195 \\
(0.000186) \\
-0.00129 \\
(0.00122) \\
0.000103 \\
(0.000106) \\
0.00106 \\
(0.00100) \\
0.000324 \\
(0.000307)\end{array}$ \\
\hline $\begin{array}{l}\text { Edr1960 x } \\
\text { c2a: in } \\
\text { utero + 0-5 } \\
\text { years }\end{array}$ & 4 & $\begin{array}{l}-0.000324 \\
(0.00120) \\
3.01 \mathrm{e}-05 \\
(0.000112) \\
0.000120 \\
(0.000445) \\
0.000174 \\
(0.000648)\end{array}$ & $\begin{array}{l}-0.000143 \\
(0.000885) \\
-4.21 \mathrm{e}-05 \\
(0.000260) \\
-1.35 \mathrm{e}-05 \\
(8.36 \mathrm{e}-05) \\
0.000199 \\
(0.00123)\end{array}$ & $\begin{array}{l}0.000680 \\
(0.000751) \\
0.000301 \\
(0.000332) \\
9.11 \mathrm{e}-05 \\
(0.000101) \\
-0.00107 \\
(0.00118)\end{array}$ & $\begin{array}{l}-3.52 \mathrm{e}-05 \\
(0.00119) \\
9.67 \mathrm{e}-06 \\
(0.000327) \\
1.14 \mathrm{e}-05 \\
(0.000385) \\
1.41 \mathrm{e}-05 \\
(0.000477)\end{array}$ & $\begin{array}{l}-0.00107 \\
(0.00104) \\
0.000394 \\
(0.000383) \\
0.000324 \\
(0.000315) \\
0.000348 \\
(0.000339)\end{array}$ & $\begin{array}{l}-0.000232 * \\
(0.000120) \\
-0.00153 * * \\
(0.000779) \\
0.000122 \\
(7.93 \mathrm{e}-05) \\
0.00126 * * \\
(0.000640) \\
0.000385 * \\
(0.000198)\end{array}$ \\
\hline $\begin{array}{l}\text { Edr1960 x } \\
\text { c3a: } 0-5 \\
\text { years }\end{array}$ & $\begin{array}{l}4 \\
5\end{array}$ & $\begin{array}{l}0.000286 \\
(0.000899) \\
-2.66 \mathrm{e}-05 \\
(8.36 \mathrm{e}-05) \\
-0.000106 \\
(0.000332) \\
-0.000154 \\
(0.000483)\end{array}$ & $\begin{array}{l}0.000351 \\
(0.000669) \\
0.000103 \\
(0.000197) \\
3.31 \mathrm{e}-05 \\
(6.33 \mathrm{e}-05) \\
-0.000487 \\
(0.000929)\end{array}$ & $\begin{array}{l}0.000568 \\
(0.000562) \\
0.000251 \\
(0.000248) \\
7.60 \mathrm{e}-05 \\
(7.59 \mathrm{e}-05) \\
-0.000895 \\
(0.000885)\end{array}$ & $\begin{array}{l}-1.73 \mathrm{e}-05 \\
(0.000865) \\
4.74 \mathrm{e}-06 \\
(0.000238) \\
5.59 \mathrm{e}-06 \\
(0.000280) \\
6.92 \mathrm{e}-06 \\
(0.000347)\end{array}$ & $\begin{array}{l}-0.000556 \\
(0.000799) \\
0.000205 \\
(0.000295) \\
0.000169 \\
(0.000243) \\
0.000181 \\
(0.000261)\end{array}$ & $\begin{array}{l}-0.000158^{*} \\
(8.95 \mathrm{e}-05) \\
-0.00105 * \\
(0.000582) \\
8.34 \mathrm{e}-05 \\
(5.73 \mathrm{e}-05) \\
0.000860 * \\
(0.000477) \\
0.000263 * \\
(0.000147) \\
4,613\end{array}$ \\
\hline
\end{tabular}

c. Health-related lifestyle choices

\begin{tabular}{lcccc}
\hline \multicolumn{1}{c}{ Variables } & Smoking & Alcohol & Exercise & $\begin{array}{c}\text { Household } \\
\text { agricultural work }\end{array}$ \\
\hline Edr1960 x c1a: in utero & 0.00227 & $0.00287^{*}$ & 0.000290 & -0.00164 \\
Edr1960 x c2a: in utero & $(0.00151)$ & $(0.00163)$ & $(0.00298)$ & $(0.0146)$ \\
+ 0-5 years & -0.000106 & -0.000891 & 0.00125 & -0.00673 \\
Edr1960 x c3a: 0-5 & $(0.000917)$ & $(0.00101)$ & $(0.00190)$ & $(0.00911)$ \\
years & 0.000462 & -0.000193 & $0.00365^{* *}$ & -0.00308 \\
Observations & $(0.000682)$ & $(0.000762)$ & $(0.00145)$ & $(0.00668)$ \\
\hline
\end{tabular}


The results in Table 8 show that all cohorts exposed to the Famine had lower adulthood height attainment. The largest negative impact was a height reduction of $0.08 \mathrm{~cm}$ felt by the cohort (Cohort 2a) that had both in utero and early childhood exposure. Moreover, Cohort 1a and 3 a were less likely to be overweight and Cohort 1a is less likely to suffer from hypertension.

Regarding mental health, our results show lower probabilities of feeling "completely satisfied" and "very satisfied" with life, and higher probabilities for feeling "not very satisfied" and "not at all satisfied" for cohort $2 \mathrm{a}$ and $3 \mathrm{a}$. As for health-related lifestyle choices, we find that Cohort 1a had a higher probability of consuming alcohol, and that Cohort $3 \mathrm{a}$ had a higher probability of doing physical exercise.

Overall the estimation results with 3 treatment cohorts are consistent with those obtained with 5 treatment cohorts. The magnitudes of the estimated marginal effects of the Famine on long term health indicators were similarly small.

\subsection{Quantile analysis}

Exposure to Famine may have different effects on survivors depending on, for instance, the survivors' genetic makeup. Such differential effects may be especially pronounced with respect to height (Chen and Zhou, 2007). To get an idea about the Famine's differential effects on height, we use quantile regressions to estimate the effects for the $0.1,0.5$ and 0.9 quantiles. The results (presented in Table 9) show that the Famine had a greater impact on individuals in the lower quantile of the distribution for some cohorts. Take cohort 4 (that had the largest height reduction by the OLS estimation), the 0.1 quantile had $0.15 \mathrm{~cm}$ height reduction compared to $0.07 \mathrm{~cm}$ for the 0.5 quantile and not statistically significant height reduction for the 0.9 quantile. However this pattern was not present for all cohorts. For instance, for Cohort 2 , the 0.5 quantile had a height reduction of $0.09 \mathrm{~cm}$, whereas the estimates were not statistically significant for the 0.1 and 0.9 quantiles. 
Table 9. Quantile regressions

\begin{tabular}{lccc}
\hline Variables & \multicolumn{3}{c}{ Height } \\
\cline { 2 - 4 } & 0.1 & 0.5 & 0.9 \\
\hline & & & \\
Edr1960 x c1: in utero & -0.0357 & $-0.0633^{*}$ & -0.0552 \\
& $(0.0486)$ & $(0.0334)$ & $(0.0509)$ \\
Edr1960 x c2 in utero + $1^{\text {st }}$ & -0.0556 & $-0.0915 * * *$ & 0.0146 \\
year & $(0.0465)$ & $(0.0319)$ & $(0.0488)$ \\
& & & \\
Edr1960 x c3 in utero + $1^{\text {st }}$ & $-0.137 * * *$ & $-0.0774 * * *$ & $-0.0992 * * *$ \\
year + 1-5 years & $(0.0365)$ & $(0.0251)$ & $(0.0383)$ \\
& & & \\
Edr1960 x c4: $1^{\text {st }}$ year + 1-5 & $-0.158 * * *$ & $-0.0757 * *$ & -0.0764 \\
years & $(0.0447)$ & $(0.0307)$ & $(0.0469)$ \\
& & & \\
Edr1960 x c5: $1-5$ years & $-0.0667 * * *$ & $-0.0598 * * *$ & $-0.0461 *$ \\
Edr1960 & $(0.0231)$ & $(0.0158)$ & $(0.0242)$ \\
& -0.0247 & $-0.0300 * * *$ & 0.0022 \\
Constant & $(0.0157)$ & $(0.0108)$ & $(0.0164)$ \\
& $148.1 * * *$ & $155.3 * * *$ & $162.5 * * *$ \\
Observations & $(0.364)$ & $(0.249)$ & $(0.381)$ \\
\hline
\end{tabular}

\section{Conclusion}

Based on a 2011 national survey of people in or entering retirement, we use the differencein-differences approach to estimate the long-term health effects for different birth-cohorts exposed to the Famine during different stages of their early childhood. We find that exposure to the Famine reduced adult height for all cohorts and had some negative impact on mental health for some cohorts. We have not found evidence to suggest that exposure to the Famine had increased the risks for diabetes, hypertension and other chronic diseases, or had consistently influenced health-related lifestyle choices.

Notably where we have detected statistically significant negative long-term health effects, their estimated magnitudes were rather small. It seems therefore that the Famine survivors were resilient enough both physically and emotionally to recover from the extreme deprivations experienced in their early childhood.

In this study we have not explored whether there were certain conditions which may have helped or hindered individuals' coping with and recovering from early childhood adversity. Also we have not considered whether the Famine had other potential adverse effects on the 
individuals exposed to it, for instance, the Famine's impact on human capital accumulation and income earning capacities. These are questions that warrant investigation in future studies. 


\section{References}

Alderman, H., Hodinott, J., \& Kinsey, B. (2006). Long term consequences of early childhood malnutrition. Oxford Economic Papers, 58, 450-474.

Almond, D. (2006). Is the 1918 influenza pandemic over? Long-term effects of in utero influenza exposure in the post-1940 U.S. population. Journal of Political Economy, 114, 672-712 (August).

Almond, D., \& Chay, K. (2006). The long run and intergenerational impact of poor infant health: evidence from cohorts born during civil rights era. New York: NY (Columbia University) and Berkeley, CA (University of California at Berkeley), Working Paper.

Almond, D., Edlund, L., Li, H., \& Zhang, J. (2007). Long-term effects of the 1959 - 1961 China famine: Mainland China and Hong Kong. NBER Working Paper, 13384.

An, M.Y., Li, W., Yang, D.T., (2001). China's Great Leap: Forward or backward? Anatomy of a central planning disaster, CEPR Discussion Paper No. 2824.

Ashton, B., Kenneth, H., Piazza, A., Zeitz, R., (1984). Famine in China, 1958-61. Population and Development Review 10(4), 613-645.

Barker, D., (1989). Mothers, Babies and Health in Later Life. Churchill Livingstone, Edinburgh.

Barker, D., (1992). Foetal and Infant Origins of Adult Disease. British Medical Journal, London.

Bleker, O. P., Roseboom, T. J., Ravelli, A. C. J., van Montfrans, G. A., Osmond, C., \& Barker, D. J. P. (2005). Cardiovascular disease in survivors of the Dutch famine. The impact of maternal nutrition on the offspring. Nestle Nutrition workshop series. Paediatric Program, vol. 55.

Behrman, J. R., \& Rosenzweig, M. (2004). Returns to birthweight. The Review of Economics and Statistics, 86(2), 586-601. 
Chen, Y., \& Zhou, L.-A. (2007). The Long-term health and economic consequences of the 1959-1961 famine in China. Journal of Health Economics, 26, 659-681.

Gørgens, T., Meng, X., \& Vaithianathan, R. (2012). Stunting and selection effects of famine: A case study of the Great Chinese Famine. Journal of Development Economics, 97(1), 99-111.

Hertzman, C., \& Power, C., (2003). Health and human development: understanding from lifecourse research. Developmental Neuropsychology 24 (2-3), 719-744.

Hertzman, C., \& Wiens, M. (1996). Child development and long-term outcomes: a population health perspective and summary of successful interventions. Social Sciences and Medicine 43, 1083-1095.

Heymann, J., Hertzman, C., Barer, M., \& Evans, R., (2005). Healthier Societies: From Analysis to Action. Oxford University Press.

Jirtle, R. L., \& Skinner, M. K. (2007). Environmental epigenomics and disease susceptibility. Nature Review Genetics, 8(4), 253-262.

Li, W., \& Yang, D. T. (2005). The Great Leap Forward: Anatomy of a Central Planning Disaster. Journal of Political Economy, 113(4), 840-877.

Lin, J.Y., (1990). Collectivization and China's agricultural crisis in 1959-1961. Journal of Political Economy 98, 1228-1252.

Lin, J.Y., \& Yang, D.T., (2000). Food availability, entitlements and the Chinese famine of 1959-61. Economic Journal 110 (460), 136-158.

Lindeboom, M., Van den Berg, G. J., \& Portrait, F. (2006). Economic conditions early in life and individual mortality. The American Economic Review, 96(1), 290-302 (March).

Luo, Z., Mu, R., \& Zhang, X. (2006). Famine and overweight in China. Review of Agricultural Economics, 28(3), 296-304. 
Maccini, S., \& Yang, D. (2009). Under the weather: Health, schooling, and socioeconomic consequences of early-life rainfall. The American Economic Review, 99(3), 1006-1026 (June).

Meng, X., \& Qian, N. (2009). The long run impact of childhood malnutrition: Evidence from China's great famine. NBER Working Paper, 14973.

Mu, R., \& Zhang, X. (2008). Gender difference in the long-term impact of famine. IFPRI Discussion Paper, 00760.

Neugebauer, R., Hoek, H., \& Susser, E. (1999). Prenatal exposure to wartime famine and development of antisocial personality disorder in early adulthood. Journal of the American Medical Association, 282(5), 455-462.

Peng, X. (1987). Demographic consequences of the great leap forward in China's provinces. Population and Development Review, 13 (4), 639-670.

Roseboom, T. J., van der Meulen, J. H. P., Ravelli, A. C. J., Osmond, C., Barker, D. J. P., \& Bleker, O. P. (2001). Effects of prenatal exposure to the Dutch famine on adult disease in later life: an overview. Molecular and Cellular Endocrinology, 185(1-2), 93-98.

Shi, X. (2011). Famine, fertility, and fortune in china. China Economic Review, 22(2), 244259.

Stein, Z., Susser, M., Saenger, G., \& Marolla, F. (1975). Famine and human development: The Dutch hunger winter of 1944-1945. New York: London and Toronto: Oxford University Press.

Yang, D., \& Su, F. (1998). The politics of famine and reform in rural China. China Economic Review, 2, 141-156. 


\section{Appendices}

Table A1. Regional variations in Famine duration

$\begin{array}{ll}\text { Famine years } & \text { Provinces } \\ 58-60 & \text { Anhui, Gansu, Ningxia, Qinghai, Yunnan } \\ 58-61 & \text { Guizhou } \\ 58-62 & \text { Chongqing, Sichuan } \\ 59-60 & \text { Henan, Hubei,Inner Mongolia, Jiangxi, Shannxi, Xinjiang, Zhejiang } \\ 59-61 & \text { Beijing, Guangxi, Hebei, Heilongjiang, Hunan, Jiangsu, Jilin, Liaoning, Shandong, Shanghai } \\ 59-62 & \text { Tianjin } \\ 1960 & \text { Fujian } \\ & \text { Shanxi }\end{array}$

Table A2. Variable definitions

\section{Variable \\ Definition}

\section{Independent variables}

Physical health

Height

Overweight

Diabetes

Hypertension

Chronic diseases

\section{Mental health}

Depression

Hopeful

Happy

Lonely
An individual's height in centimetres in 2011

Binary variable, $=1$ if an individual has a $\mathrm{BMI} \geq 25$; and 0 otherwise

Binary variable, $=1$ if an individual has diabetes; and 0 otherwise

Binary variable, $=1$ if an individual has hypertension; and 0 otherwise

Binary variable, $=1$ if an individual has at least one of the following chronic diseases: cancer, liver diseases, lung diseases, heart problems, stroke, kidney diseases, and stomach diseases ; and 0 otherwise

The frequency of an individual feeling depressed in the past week.

$=1$ Rarely or none of the time;

$=2$ Some or little of the time ( $<1$ day);

$=3$ Occasionally or a moderate amount of the time (3-4 days);

$=4$ Most or all of the time (5-7 days)

The frequency of an individual feeling hopeful in the past week.

$=1$ Rarely or none of the time;

$=2$ Some or little of the time $(<1$ day);

$=3$ Occasionally or a moderate amount of the time (3-4 days);

$=4$ Most or all of the time (5-7 days)

The frequency of an individual feeling happy in the past week

$=1$ Rarely or none of the time;

$=2$ Some or little of the time ( $<1$ day);

$=3$ Occasionally or a moderate amount of the time (3-4 days);

$=4$ Most or all of the time (5-7 days)

The frequency of an individual feeling lonely in the past week.

$=1$ Rarely or none of the time;

$=2$ Some or little of the time $(<1$ day);

$=3$ Occasionally or a moderate amount of the time (3-4 days);

$=4$ Most or all of the time (5-7 days) 
Cannot continue life

Unsatisfied with life

\section{Smoking}

Alcohol

Exercise

Household agricultural work

\section{Explanatory variables}

Age

Gender

No schooling

Primary education

Middle or higher education

Employment

Edr

Edr1960

\section{Treatment cohorts ${ }^{1}$}

C1: in utero

$\mathrm{C} 2$ : in utero $+1^{\text {st }}$ year

C3: in utero $+1^{\text {st }}$ year $+1-5$ years

C4: $1^{\text {st }}$ year $+1-5$ years

C5: 1-5 years
The frequency of an individual feeling he/she could not continue life in the past week. $=1$ Rarely or none of the time;

$=2$ Some or little of the time $(<1$ day);

$=3$ Occasionally or a moderate amount of the time (3-4 days);

$=4$ Most or all of the time (5-7 days)

The extent to which an individual felt unsatisfied with life as a whole.

$=1$ completely satisfied;

$=2$ very satisfied;

$=3$ somewhat satisfied;

$=4$ not very satisfied

$=5$ not at all satisfied

Binary variable, $=1$ if a person has ever chewed tobacco, smoked a pipe, smoked selfrolled cigarettes, or smoked cigarettes/cigars.

Binary variable, $=1$ if an individual drank any alcoholic beverages, such as beer, wine, or liquor in the past year.

Binary variable, $=1$ if an individual exercise continuously for at least 10 minutes in a usual week; and zero otherwise.

Hours per day an individual spent on household agricultural work

Age of the individual in 2011

binary variable $=1$ for male, and 0 for female

The individual did not receive school education

The highest level of education attained by an individual is completion of primary school.

The highest level of education attained by an individual is completion of middle school or higher education

Binary variable, $=1$ if an individual worked more than one month in the past year or received wages from his/her current workplace or from a dispatch/contract company.

Excess death rate calculated as the difference between the actual death rate in a Famine year and the average death rate for the 3 years before the Famine

Excess death rate for year 1960, the worst year of the Famine.

Cohort 1: the cohort exposed to the Famine only in utero

It includes individuals born between January and September of 1962.

Cohort 2: the cohort exposed to the Famine in utero and during their first year of life. It includes individuals born in 1961.

Cohort 3: the cohort exposed to the Famine in utero, during their first year of life and in early childhood. It includes individuals born between October 1959 and December 1960.

Cohort 4: the cohort exposed to the Famine in their first year of life and in early childhood. It includes individuals born between February 1958 and September of 1959.

Cohort 5: the cohort exposed to the Famine only in early childhood. It includes individuals born between 1954 and January 1958. 